\title{
MRI in familial breast cancer
}

\author{
K. G. A. Gilhuijs ${ }^{a}$, E. E. Deurloo ${ }^{a, b}$ \\ aDepartment of Radiology, The Netherlands Cancer Institute/Antoni van Leeuwenhoek Hospital; \\ ${ }^{b}$ Department of Radiology, Academic Medical Center, Amsterdam, The Netherlands.
}

\begin{abstract}
Five to ten per cent of all breast cancers are associated with a proven genetic predisposition for the disease or a strong family history of breast cancer in which yet unknown genetic predisposition is suspected. Carriers of germline mutations in genes breast cancer 1 or 2 (BRCA1/2) have up to $85 \%$ chance of developing breast cancer during their lifetime. The majority of these women develop the disease before the age of 50 years. Consequently, breast-cancer screening programmes aimed at reducing mortality in this population may only be effective if they start at much younger age than the general breast-cancer screening programmes. Unfortunately, the efficacy of conventional X-ray mammography in premenopausal women is often limited by dense fibroglandular tissue that obscures suspicious lesions. As a result, more advanced breast-imaging techniques have been considered, such as contrast-enhanced (CE) magnetic resonance imaging (MRI). In symptomatic patients, the sensitivity of CE MRI to detect invasive breast cancer is known to be high, regardless of the density of the fibroglandular tissue. Conversely, the specificity of CE MRI to discriminate between benign and malignant lesions is variable, and depends on the indication of the examination. Low specificity could result in many recalls on benign lesions, thus negatively affecting the cost-benefit ratio of CE MRI as a screening technique. Several single- and multi-institutional studies have been performed to investigate the efficacy of CE MRI as a screening tool exclusively for asymptomatic women at increased lifetime risk of breast cancer. Mounting evidence suggests that the addition of CE MRI results in cost-effective detection of tumours at earlier stage in BRCA1/2 mutation carriers. The value of CE MRI in other populations at risk is currently uncertain, and it is unlikely that CE MRI will be cost efficient in the general screening population of women who are not at increased lifetime risk.
\end{abstract}

Keywords: Familial breast cancer; Germline mutation; BRCA1/2; CE MRI; Fibroglandular tissue; Breastcancer screening

\section{Introduction}

Breast cancer is a major cause of mortality among women in western countries. In the Netherlands, approximately 10000 new cases of breast cancer are diagnosed each year and 3500 die of the disease [1].

Correspondence to: K. G. A. Gilhuijs, Department of Radiology, The Netherlands Cancer Institute/Antoni van Leeuwenhoek Hospital, Plesmanlaan 121, 1066 CX Amsterdam, The Netherlands. Tel: +31-20512-2941; Fax: +31-20-512-2934

Publication date 17/12/04 BCO/218/2004/FO
Breast cancer constitutes nearly one-third of all cancers in women. In 5-10\% of the cases the cancer is associated with a proven genetic predisposition [2-4], or a strong family history of breast cancer [5]. Germline mutations in two genes, breast cancer 1 and 2 (BRCA1 and BRCA2, respectively), account for approximately $50 \%$ of the genetically induced breast cancers $[3,4]$. The remaining cancers are suspected to be caused by other, yet unidentified, gene mutations. Women with mutations in BRCA1/2 have up to $85 \%$ risk of developing breast cancer sometime during their lifetime [6]. Moreover, genetically induced 
cancers typically develop at considerably younger age than sporadic breast cancers, and are typically more aggressive. At the age of 50 years, more than half the population of women who carry mutations in the BRCA1/2 genes are diagnosed with high-grade, rapidly growing breast cancers with pushing borders and negative hormone receptors [7-10]. As these factors are associated with poor prognosis of diseasefree survival, several strategies are pursued to reduce mortality: prophylactic surgery (mastectomy, oophorectomy), chemoprevention, and surveillance.

Although prophylactic surgery and chemoprevention considerably reduce the risk of breast cancer (by $90 \%$ and $49 \%$, respectively) $[11,12]$, a significant proportion of BRCA1/2 mutation carriers are more inclined towards surveillance as a first option [13]. Surveillance typically constitutes semi-annual physical examination and annual mammography from age 25 years onwards [14]. The efficacy of mammography screening to reduce mortality in premenopausal women at increased lifetime risk of breast cancer - as opposed to reducing mortality caused by sporadic cancers in postmenopausal women - is, however, largely unproven and subject of debate. This overview discusses the limitations of conventional breast imaging to screen women at increased lifetime risk of breast cancer, as well as the complementary value, pitfalls, and current consensus on the use of contrast-enhanced (CE) magnetic resonance imaging (MRI) for this purpose.

\section{Mammography}

Owing to its widely accepted cost-benefit ratio and general availability, X-ray mammography still is the primary method to detect breast cancers. An updated overview of the Swedish randomized trials confirmed that breast-cancer screening with mammography in women between 50 and 70 years results in a significant reduction (21\%) of breast-cancer mortality [15]. Nonetheless, there are concerns as to whether mammography retains its efficacy in the screening of premenopausal women at increased lifetime risk of breast cancer. Approximately $40-50 \%$ of the mammograms of premenopausal women may not provide sufficient information to exclude presence of cancer because it is obscured by dense fibroglandular tissue [16-18]. The sensitivity of mammography in this age group may be as low as $25 \%$ [19-23]. Atypical manifestation of genetically induced cancers (round, well-circumscribed masses) may further attribute to misinterpretation of cancers as benign lesions $[10,23,24]$. In addition to the limited sensitivity to detect breast cancers in premenopausal women, concern exists about radiation exposure to women carrying BRCA1/2 germline mutations, especially starting at a young age [25]. This concern led to recommendations on a lower limit to the screening interval, thus weighing the risk of (rapidly growing) interval cancers against the risk of radiation-induced cancers at a later age. Nonetheless, concerns about mammography-induced cancers currently have neither been validated nor refuted in studies concerning actual screening populations of premenopausal women. Despite these pitfalls, mammography currently still is the most sensitive examination for the detection of ductal carcinoma in situ (DCIS) [26], thus allowing identification of cancers before they potentially reach an invasive stage.

\section{Ultrasonography}

Ultrasonography is typically employed as an adjunct to mammography to follow up on suspicious lesions. It has proven effective in the differentiation between cystic and solid masses, and in guidance to biopsy. Major limitations are, however, the dependence of the technique on the experience of the operator, the inability to detect most pre-invasive cancers and a significant percentage of small $(<1 \mathrm{~cm})$ non-palpable invasive cancers [27]. Despite these limitations, ultrasonography has proven to be useful in the visualization of suspected cancers within mammographically dense tissue. Consequently, the technique is also evaluated as a screening tool for premenopausal women at increased lifetime risk of breast cancer. So far, these studies have reported moderate to low sensitivity: Warner et al. [28] detected 7 of 22 cancers and Podo et al. [29] detected 1 of 8 cancers.

\section{CE MRI of symptomatic women}

CE MRI employs magnetic and radio frequency fields to visualize the uptake of an MRI-specific contrast agent (gadolinium-DTPA) [30]. Applied intravenously, this agent results in enhancement of areas in the breast that correspond to increased blood flow, capillary permeability, and extracellular volume $[31,32]$. As these factors are associated with angiogenesis in breast tumours, CE MRI thus visualizes functional processes rather than tissue density. Without the use of contrast agent, MRI is of very little value to detect breast cancers. Currently, CE MRI of the breast is known to be the most sensitive modality to detect invasive breast cancer, yielding sensitivities approaching 100\% [33-36]. Sensitivity is not impaired by dense parenchyma. Moreover, the technique is known to detect breast cancers that are undetected at mammography even when the breast tissue is not dense $[37,38]$. In addition, MRI does not employ ionizing radiation. These virtues could make MRI particularly 
suitable for the examination of premenopausal women at increased lifetime risk.

At present, CE MRI does, however, present a number of drawbacks. First, its sensitivity to detect DCIS is inferior compared to that of mammography, and can be as low as $45 \%[39,40]$. Secondly, the specificity of CE MRI to discriminate between benign and malignant lesions varies between $37 \%$ and $90 \%$ depending on the indication $[33,36]$. Particularly in young premenopausal women, benign findings such as fibroadenomas, adenosis, or hormone-induced enhancement of normal parenchyma are far more common than carcinomas (e.g. Ref. [23]). The CE MRI characteristics of these benign findings are often similar to those of malignant lesions, and the lack of standardized interpretation guidelines in the past have led to inter-reader variations that further contributed to varying specificity. Current consensus dictates that morphological characteristics of contrast uptake (e.g. shape, margins) as well as temporal characteristics (e.g. speed of uptake, presence of washout) must be considered in the interpretation of CE MRI data [41]. Nonetheless, contrary to the standardized mammography examination, CE MRI of the breast uses various imaging protocols that differ between hospitals. Some techniques emphasize on morphological characteristics, other on temporal, yet other aim at a balance.

Obtaining histopathological proof of suspicious lesions that are only visible at CE MRI can be a daunting task. If the lesion cannot be localized using targeted second-look ultrasonography, an MRIcompatible biopsy device may be an option. However, although these devices are currently out on the market, only a small number of institutions have experience with them, and they often turn out to be ineffective for small $(<1 \mathrm{~cm})$ lesions. Excisional biopsies may cause scarring and architectural distortions that interfere with future screening efforts. Moreover, frequent biopsies on benign lesions are not desirable in a screening setting. Evidence from mammography screening suggests that further workup on lesions that turn out to be benign causes significant psychological distress that may persist months after the final diagnosis has been given [42]. Especially in a population of women who are quite aware of their high risk, biopsies on benign lesions are greatly undesirable. An often applied compromise is shortterm follow-up by CE MRI of equivocal and possibly benign lesions. Although this approach resolves the diagnosis of many benign lesions that are caused by hormone-related enhancement, it increases the risk of delaying cancer diagnosis, which is particularly undesirable for the (rapidly growing) genetically induced breast cancers. In light of these limitations, computer programs are being developed to assist radiologists in identifying benign lesions with high certainty, yielding promising initial results $[43,44]$. Other drawbacks of CE MRI are the restrictions to perform the examination during the second week of the cycle in order to minimize hormone-induced enhancement, the usual contraindications (such as pace makers, aneurysm clips, claustrophobia), and most notably, its relatively high cost.

Despite its limitations, the unmatched sensitivity of CE MRI for invasive breast cancer has warranted its use for a number of selected indications: suspicion of multifocal tumour, detection of unknown primary tumour with positive lymph nodes, and suspicion of recurrence after breast-conserving surgery.

\section{CE MRI of asymptomatic women at increased lifetime risk}

In the past decade, single-institutional studies as well as multi-institutional trials in the UK, USA, Canada, Italy, Germany and the Netherlands focused on the complementary value of CE MRI to mammography to detect breast cancer in women at increased lifetime risk. First results demonstrate the ability of $\mathrm{CE}$ $M R I$ to increase the sensitivity to detect tumours in BRCA1/2 mutation carriers, and to detect malignancies at earlier stage. Typically, detected tumours were $<1 \mathrm{~cm}$ in size and had not yet spread to the axillary nodes. Kriege et al. [45] reported the results of the Dutch multi-institutional study in which nearly 2000 women participated with a median follow-up of 2.9 years (Table 1). The fraction of invasive tumours that were $\leqslant 10 \mathrm{~mm}$ in size was significantly greater in the screening group (43\%) than in two matched control groups (14\% and $13 \%$, respectively). In addition, the combined incidence of tumour-positive lymph nodes (micrometastases and macrometastases) in invasive breast cancer was significantly smaller in the screening group (21\% vs. $52 \%$ and $56 \%$ ).

Although all studies agree that screening by CE MRI may be of particular benefit to women at high lifetime risk of breast cancer, that is, women with proven BRCA1/2 mutation carriers, a number of issues require further investigation before definite guidelines can be formulated concerning which women at risk should be screened, and how the information from the various screening modalities should be combined $[46,47]$. These issues include the sensitivity of CE MRI for DCIS, specificity for invasive as well as for in situ cancer, cost-benefit, and impact on mortality.

An accurate assessment of the complementary value of CE MRI to mammography for the detection of DCIS in premenopausal women at risk can currently not be made owing to the small number of DCIS cases included in these studies so far. Evidence suggests, however, that CE MRI cannot replace 
Table 1. Prospective studies comparing the efficacy of conventional breast imaging (mammography, ultrasonography) with the efficacy of contrast-enhanced MRI in the screening of women at increased lifetime risk of breast cancer.

\begin{tabular}{|c|c|c|c|c|c|c|}
\hline Study & Sensitivity & Specificity & $\begin{array}{l}\text { Number of } \\
\text { women }\end{array}$ & $\begin{array}{l}\text { Number of } \\
\text { validated } \\
\text { screens }^{\mathrm{a}}\end{array}$ & $\begin{array}{l}\text { Fraction } \\
\text { DCIS }^{b}\end{array}$ & Inclusion $^{c}$ \\
\hline $\begin{array}{l}\text { Kuhl et al. [23] } \\
\text { Mammography } \\
\text { Ultrasonography } \\
\text { CE MRI }\end{array}$ & $\begin{array}{ll}0 / 3 & (0 \%) \\
3 / 9 & (33 \%) \\
9 / 9 & (100 \%)\end{array}$ & $\begin{array}{ll}89 / 96 & (93 \%) \\
77 / 96 & (80 \%) \\
91 / 96 & (95 \%)\end{array}$ & 192 & 105 & $2 / 9$ (33\%) & $\begin{array}{l}\mathrm{AW}+\mathrm{SW}+ \\
\mathrm{PH}+\mathrm{MC}+\mathrm{FH}\end{array}$ \\
\hline $\begin{array}{l}\text { Tilanus-Linthorst et al. [22] } \\
\text { Mammography } \\
\text { Ultrasonography } \\
\text { CE MRI }\end{array}$ & $\begin{array}{l}0 / 3(0 \%) \\
- \\
3 / 3(100 \%)\end{array}$ & $\begin{array}{l}- \\
- \\
100 / 106(94 \%)\end{array}$ & 109 & 109 & $0 / 3(0 \%)$ & $\mathrm{AW}+\mathrm{MC}+\mathrm{FH}$ \\
\hline $\begin{array}{l}\text { Warner et al. [28] } \\
\text { Mammography } \\
\text { Ultrasonography } \\
\text { CE MRI }\end{array}$ & $\begin{array}{l}8 / 22(36 \%) \\
7 / 22(32 \%) \\
17 / 22(77 \%)\end{array}$ & $\begin{array}{ll}456 / 457 & (100 \%) \\
433 / 450 & (96 \%) \\
437 / 457 & (96 \%)\end{array}$ & 236 & 479 & 6/22 (27\%) & $\mathrm{AW}+\mathrm{MC}+\mathrm{PH}+\mathrm{DM}$ \\
\hline $\begin{array}{l}\text { Podo et al. [29] } \\
\text { Mammography } \\
\text { Ultrasonography } \\
\text { CE MRI }\end{array}$ & $\begin{array}{ll}1 / 8 & (13 \%) \\
1 / 8 & (13 \%) \\
8 / 8 & (100 \%)\end{array}$ & $\begin{array}{l}97 / 97(100 \%) \\
97 / 97(100 \%) \\
96 / 97(99 \%)\end{array}$ & 105 & 105 & $3 / 8$ (38\%) & $\mathrm{AW}+\mathrm{MC}+\mathrm{FH}+\mathrm{PH}$ \\
\hline $\begin{array}{l}\text { Kriege et al. }[45]^{d} \\
\text { Mammography } \\
\text { Ultrasonography } \\
\text { CE MRI }\end{array}$ & $\begin{array}{l}18 / 45(40 \%) \\
- \\
32 / 45(71 \%)\end{array}$ & $\begin{array}{l}3917 / 4124(95 \%) \\
- \\
3704 / 4124(90 \%)\end{array}$ & 1909 & 4169 & $6 / 51 \quad(12 \%)$ & $\mathrm{AW}+\mathrm{MC}+\mathrm{FH}$ \\
\hline
\end{tabular}

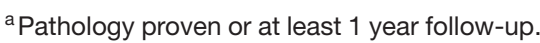

${ }^{b}$ Fraction of DCIS among the total number of cancers found.

${ }^{\mathrm{c}} \mathrm{AW}$ : asymptomatic women; SW: symptomatic women; $\mathrm{PH}$ : personal history of breast/ovarian cancer; MC: mutation carriers; $\mathrm{FH}$ : family history; DM: dense mammograms.

${ }^{\mathrm{d}}$ Diagnostic indices reflect accuracy at BI-RADS cutoff score 3 (probably benign).

mammography for the detection of DCIS. In the largest study published to date, Kriege et al. report that CE MRI failed to visualize 5 of 6 DCIS cases that were visible at mammography [45].

The reported specificity of CE MRI to differentiate between benign and malignant findings in the highrisk screening population ranges between $90 \%$ and $99 \%$. These specificities are consistently high, and are in contrast with those reported in symptomatic patients. The discrepancy is mostly caused by the fact that the majority of examinations of asymptomatic women do not show any suspicious enhancement at all. These 'normal' findings are generally grouped in the category 'benign'. It will obviously be more challenging, however, to differentiate between benign and malignant enhancement than to differentiate between 'no enhancement' and malignant enhancement. The positive-predictive value (the percentage of malignant tumours in the total set of abnormal scans that prompted further workup) more accurately reflects the ability to differentiate between benign and malignant areas of enhancement, and does show considerable variation between studies (Table 2). Several explanations exist for this variation. First, differences in opinion regarding which types of workup should be counted in the calculation. Some studies consider only biopsies, while other consider any workup relevant (including short-term follow-up by CE MRI). Groups supporting the former strategy (e.g. Refs $[23,29])$ typically report higher positivepredictive values than groups supporting the latter strategy (e.g. Ref. [45]). Other reasons for variations between studies are the small numbers of included tumours (especially in the single-institutional studies), differences in age and risk level of included women, relatively short follow-up periods, and differences in interpretation guidelines for CE MRI. Recent guidelines for CE MRI according to the Breast Imaging Reporting and Data System Atlas (BI-RADS) classification [41] were not available at the time that the reported studies started. Although some employed scoring systems equivalent to the mammography BI-RADS scoring system $[23,28,45]$, other systems have been used as well [29]. It should also be kept in mind that CE MRI techniques have not been standardized across studies.

Only few groups have attempted to provide cost estimates of adding CE MRI to the surveillance programme of asymptomatic women at increased risk. Tilanus-Linthorst et al. report an additional cost of 
Table 2. Positive-predictive value of contrast-enhanced MRI in prospective studies.

\begin{tabular}{lll}
\hline Study & \multicolumn{2}{l}{ Positive-predictive value } \\
\hline Kuhl et al. [23] & $9 / 14$ & $(64 \%)$ \\
Tilanus-Linthorst et al. [22] & $3 / 9$ & $(33 \%)$ \\
Warner et al. [28] & $17 / 37$ & $(46 \%)$ \\
Podo et al. [29] & $8 / 9$ & $(89 \%)$ \\
Kriege et al. [45] & $32 / 452$ & $(7 \%)$ \\
\hline
\end{tabular}

$€ 13.930$ per detected cancer, which is approximately 1.5 times the cost of detecting a breast cancer in the Dutch general screening programme [22]. Podo et al. [29] reports only $€ 6.000$ per MRI-detected cancer, constituting two-thirds of the cost to detect a breast cancer in the general screening programme. The small number of cases studied so far, and the differences in inclusion criteria underlie these discrepancies in assessment of cost. Obviously, the larger the risk to detect breast cancer, the more cost-effective CE MRI will become. Future studies must identify subgroups of women at risk who benefit most from screening by CE MRI in terms of reduced mortality as well as in terms of reduced morbidity.

\section{Conclusions}

The endpoint of any screening programme is reduction of mortality. Only a prospective randomized trial can assess this endpoint, and no evidence currently exists that the addition of CE MRI to the surveillance programme of women at high risk reduces mortality. Nonetheless, mounting evidence exists that the addition of CE MRI results in cost-effective detection of tumours at earlier stage in BRCA1/2 mutation carriers. The value of $C E M R I$ in other populations at risk is currently uncertain. Moreover, it is unlikely that $\mathrm{CE}$ $\mathrm{MRI}$ will be cost efficient in the general screening population of women who are not at increased lifetime risk.

\section{References}

1. Research Committee of the Netherlands Cancer Registry. Incidence of cancer in the Netherlands 1999/2000. 2003; 1.0 .

2. Easton DF, Bishop DT, Ford D, Crockford GP. Genetic linkage analysis in familial breast and ovarian cancer: results from 214 families. The Breast Cancer Linkage Consortium. Am J Hum Genet 1993; 52: 678-701.

3. Miki Y, Swensen J, Shattuck-Eidens D, et al. A strong candidate for the breast and ovarian cancer susceptibility gene BRCA1. Science 1994; 266: 66-71.

4. Wooster R, Bignell G, Lancaster J, et al. Identification of the breast cancer susceptibility gene BRCA2. Nature 1995; 378: 789-792.
5. Lynch HT, Albano WA, Danes BS, et al. Genetic predisposition to breast cancer. Cancer 1984; 53: 612-622.

6. Struewing JP, Hartge P, Wacholder S, et al. The risk of cancer associated with specific mutations of BRCA1 and BRCA2 among Ashkenazi Jews. New Engl J Med 1997; 336: 1401-1408.

7. Easton DF, Ford D, Bishop DT. Breast and ovarian cancer incidence in BRCA1-mutation carriers. Breast Cancer Linkage Consortium. Am J Hum Genet 1995; 56: 265-271.

8. Claus EB, Schildkraut JM, Thompson WD, Risch NJ. The genetic attributable risk of breast and ovarian cancer. Cancer 1996; 77: 2318-2324.

9. Johannsson OT, Idvall I, Anderson C, et al. Tumour biological features of BRCA1-induced breast and ovarian cancer. Eur J Cancer 1997; 33: 362-371.

10. Kaas R, Kroger R, Hendriks JH, et al. The significance of circumscribed malignant mammographic masses in the surveillance of BRCA $1 / 2$ gene mutation carriers. Eur Radiol 2004; 14: 1647-1653.

11. Hartmann LC, Schaid DJ, Woods JE, et al. Efficacy of bilateral prophylactic mastectomy in women with a family history of breast cancer. New Engl J Med 1999; 340: 77-84.

12. Grann VR, Jacobson JS, Whang W, et al. Prevention with tamoxifen or other hormones versus prophylactic surgery in BRCA1/2-positive women: a decision analysis. Cancer $J$ Sci Am 2000; 6: 13-20.

13. Evans D, Lalloo F, Shenton A, Boggis C, Howell A. Uptake of screening and prevention in women at very high risk of breast cancer. Lancet 2001; 358: 889-890.

14. Vasen HF, Haites NE, Evans DG, et al. Current policies for surveillance and management in women at risk of breast and ovarian cancer: a survey among 16 European family cancer clinics. European Familial Breast Cancer Collaborative Group. Eur J Cancer 1998; 34: 1922-1926.

15. Nystrom L, Andersson I, Bjurstam N, Frisell J, Nordenskjold B, Rutqvist LE. Long-term effects of mammography screening: updated overview of the Swedish randomised trials. Lancet 2002; 359: 909-919.

16. Stomper PC, D'Souza DJ, DiNitto PA, Arredondo MA. Analysis of parenchymal density on mammograms in 1353 women 25-79 years old. Am J Roentgenol 1996; 167: 1261-1265.

17. Lehman CD, White E, Peacock S, Drucker MJ, Urban N. Effect of age and breast density on screening mammograms with false-positive findings. Am $J$ Roentgenol 1999; 173: 1651-1655.

18. Zonderland HM, Coerkamp EG, Hermans J, van de Vijver MJ, van Voorthuisen AE. Diagnosis of breast cancer: contribution of US as an adjunct to mammography. Radiology 1999; 213: 413-422.

19. Shaw de Paredes E, Marsteller LP, Eden BV. Breast cancers in women 35 years of age and younger: mammographic findings. Radiology 1990; 177: 117-119.

20. Morrow M. Identification and management of the woman at increased risk for breast cancer development. Breast Cancer Res Treat 1994; 31: 53-60.

21. Peer PG, Verbeek AL, Straatman H, Hendriks JH, Holland R. Age-specific sensitivities of mammographic screening for breast cancer. Breast Cancer Res Treat 1996; 38: 153-160.

22. Tilanus-Linthorst MM, Obdeijn IM, Bartels KC, de Koning HJ, Oudkerk M. First experiences in screening women at high risk for breast cancer with MR imaging. Breast Cancer Res Treat 2000; 63: 53-60. 
23. Kuhl CK, Schmutzler RK, Leutner CC, et al. Breast MR imaging screening in 192 women proved or suspected to be carriers of a breast cancer susceptibility gene: preliminary results. Radiology 2000; 215: 267-279.

24. Tilanus-Linthorst $M$, Verhoog L, Obdeijn IM, et al. A BRCA1/2 mutation, high breast density and prominent pushing margins of a tumor independently contribute to a frequent false-negative mammography. Int $J$ Cancer 2002; 102: 91-95.

25. Feig SA. Assessment of radiation risk from screening mammography. Cancer 1996; 77: 818-822.

26. Orel SG, Mendonca MH, Reynolds C, Schnall MD, Solin LJ, Sullivan DC. MR imaging of ductal carcinoma in situ. Radiology 1997; 202: 413-420.

27. Viehweg P, Paprosch I, Strassinopoulou M, HeywangKobrunner $\mathrm{SH}$. Contrast-enhanced magnetic resonance imaging of the breast: interpretation guidelines. Top Magn Reson Imag 1998; 9: 17-43.

28. Warner E, Plewes DB, Hill KA, et al. Surveillance of BRCA1 and BRCA2 mutation carriers with magnetic resonance imaging, ultrasound, mammography, and clinical breast examination. J Am Med Assoc 2004; 292: 1317-1325.

29. Podo F, Sardanelli F, Canese R, et al. The Italian multicentre project on evaluation of MRI and other imaging modalities in early detection of breast cancer in subjects at high genetic risk. J Exp Clin Cancer Res 2002; 21: 115-124.

30. Heywang SH, Hahn D, Schmidt $\mathrm{H}$, et al. MR imaging of the breast using gadolinium-DTPA. J Comput Assist Tomogr 1986; 10: 199-204.

31. Brasch RC, Weinmann HJ, Wesbey GE. Contrastenhanced NMR imaging: animal studies using gadoliniumDTPA complex. Am J Roentgenol 1984; 142: 625-630.

32. Strich G, Hagan PL, Gerber KH, Slutsky RA. Tissue distribution and magnetic resonance spin lattice relaxation effects of gadolinium-DTPA. Radiology 1985; 154: 723-726.

33. Kelcz F, Santyr G. Gadolinium-enhanced breast MRI. Crit Rev Diagn Imag 1995; 36: 287-338.

34. Obdeijn IM, Kuijpers TJ, van Dijk P, Wiggers T, Oudkerk M. MR lesion detection in a breast cancer population. J Magn Reson Imag 1996; 6: 849-854.

35. Bone B, Pentek Z, Perbeck L, Veress B. Diagnostic accuracy of mammography and contrast-enhanced MR imaging in 238 histologically verified breast lesions. Acta Radiol 1997; 38: 489-496.

36. Heywang-Kobrunner SH, Viehweg P, Heinig A, Kuchler C. Contrast-enhanced MRI of the breast: accuracy, value, controversies, solutions. Eur J Radiol 1997; 24: 94-108.

37. Tilanus-Linthorst $\mathrm{MM}$, Obdeijn $\mathrm{Al}$, Bontenbal $\mathrm{M}$, Oudkerk M. MRI in patients with axillary metastases of occult breast carcinoma. Breast Cancer Res Treat 1997; 44: 179-182.

38. Morris EA, Schwartz LH, Dershaw DD, et al. MR imaging of the breast in patients with occult primary breast carcinoma. Radiology 1997; 205: 437-440.

39. Gilles R, Zafrani B, Guinebretiere JM, et al. Ductal carcinoma in situ: MR imaging-histopathologic correlation. Radiology 1995; 196: 415-419.

40. Westerhof JP, Fischer U, Moritz JD, Oestmann JW. MR imaging of mammographically detected clustered microcalcifications: is there any value? Radiology 1998; 207: 675-681.

41. American College of Radiology (ACR) Breast Imaging Reporting and Data System Atlas (BI-RADS ${ }^{\circledR}$ Atlas), 2003.

42. Brett J, Austoker J, Ong G. Do women who undergo further investigation for breast screening suffer adverse psychological consequences? A multi-centre follow-up study comparing different breast screening result groups five months after their last breast screening appointment. J Public Health Med 1998; 20: 396-403.

43. Gilhuijs KG, Deurloo EE, Muller SH, Peterse JL, Schultze Kool LJ. Breast MR imaging in women at increased lifetime risk of breast cancer: clinical system for computerized assessment of breast lesions initial results. Radiology 2002; 225: 907-916.

44. Deurloo EE, Muller SH, Peterse JL, Besnard APE, Gilhuijs KGA. Clinically and mammographically occult breast lesions at MR imaging: potential impact of computerized assessment on clinical reading. Radiology 2005 (in press).

45. Kriege M, Brekelmans CT, Boetes C, et al. Efficacy of $\mathrm{MRI}$ and mammography for breast-cancer screening in women with a familial or genetic predisposition. New Engl J Med 2004; 351: 427-437.

46. Liberman $\mathrm{L}$. Breast cancer screening with $\mathrm{MRI}$ - what are the data for patients at high risk? New Engl J Med 2004; 351: 497-500.

47. Robson ME, Offit K. Breast MRI for women with hereditary cancer risk. J Am Med Assoc 2004; 292: 1368-1370. 